\section{Use of the Critical Acidification Model to Estimate Critical Localized Corrosion Potentials of Duplex Stainless Steels}

\author{
Mariano A. Kappes*, Mauricio Rincón Ortiz**, \\ Mariano Iannuzzi***, Ricardo M. Carranza****
}

\section{ARTICLE INFO}

\section{Article history:}

Received Day Month Year Accepted Day Month Year Available Day Month Year

Keywords:

UNS S32750, UNS S31803, simulated crevice solutions, crevice corrosion, seawater

*Comisión Nacional de Energía Atómica, Instituto Sabato, UNSAM / CNEA CONICET, Av. Gral. Paz 1499, San Martín, B1650KNA, Buenos Aires, Argentina, kappes@cnea.gov.ar

** Universidad Industrial de Santander, Cr 27 calle 9, Bucaramanga, Santander, 680002, Colombia

*** Norwegian University of Science and Technology (NTNU) \& General Electric Eyvind Lyches vei 10 1338, Sandvika, Norway

**** Comisión Nacional de Energía Atómica, Instituto Sabato, UNSAM / CNEA, Av. Gral. Paz 1499, San Martín, B1650KNA, Buenos Aires, Argentina

*Corresponding author: +54-11-6772-7353.

Email: kappes@cnea.gov.ar

\begin{abstract}
Crevice corrosion affects the integrity of stainless steels used in components exposed to seawater. Traditionally, crevice corrosion testing involves the use of artificial crevice formers to obtain a critical crevice potential, which is a measure of the crevice corrosion resistance of the alloy. The critical acidification model proposed by Prof. J.R Galvele predicts that the critical crevice potential is the minimum potential required to maintain an acidic solution with a critical $\mathrm{pH}$ inside either a pit or a crevice. Application of Galvele's model requires an estimation of both the diffusion length and the i vs. E behavior of the metal in the solution inside the crevice.
\end{abstract}

In this work, the crevice corrosion resistance of a $22 \% \mathrm{Cr}$ duplex stainless steel (UNS S31803) and a 25\% Cr super duplex stainless steels (UNS S32750) was investigated. The i vs. E response of the two stainless steels was determined in acidified solutions of various chloride concentrations, which simulate those found in an active crevice. Critical potentials predicted by the critical acidification model were compared with critical crevice potentials measured in simulated seawater.

Results showed that despite the various assumptions and simplifications made by Galvele, the model correctly predicted the occurrence of crevice corrosion of both UNS S32750 and UNS S31803 close to room temperature in a $3.5 \mathrm{wt}$.\% NaCl environment. Critical potentials obtained by Galvele's model were similar if assuming that the chloride concentration of the simulated crevice solutions was between $7 \mathrm{M}$ and $12 \mathrm{M}$ acidified to a $\mathrm{pH}$ of 0 .

\section{INTRODUCTION}

Galvele's critical acidification model first introduced in 1976 allows the estimation of a critical potential, $E_{\text {crit }}$, if the concentration of aggressive species in pits or crevices is known ${ }^{1}$. In this model, pits and crevices are treated as the same phenomenon from an electrochemical point of view, the sole difference being the diffusion length. As noted by Galvele $e^{1,2}$, the critical potential can be estimated by measuring the anodic polarization behavior of the material of interest in pit- or crevice-like solutions prepared with reagent grade chemicals. In Galvele's model, $\mathrm{E}_{\text {crit }}$ is defined as the potential where a critical current density, $i_{\text {crit, }}$ is reached, which, for a given bulk environment, is a function of the pit or crevice depth, $x$. Because the application of the critical acidification model to estimate localized corrosion resistance requires the use of proper electrolytes simulating the pit or crevice environment, the $\mathrm{pH}$ and the chloride concentration inside pits or crevices have to be known. A brief review of the various proposed pitand crevice-like solutions in stainless steels is presented below.

For stainless steels, hydrolysis of $\mathrm{Fe}, \mathrm{Cr}$, Ni and Mo metal cations results in a decrease of the $\mathrm{pH}$ inside the pit or crevice. The maximum amount of those cations in the solution inside the pit or crevice is limited by precipitation of the corresponding metal cation chloride salt, which restricts the minimum $\mathrm{pH}$ obtainable. Metal cation salts have a solubility on the order of $4 \mathrm{M}^{3}$. Despite being in lower proportion than $\mathrm{Fe}^{2+}$, dissolved $\mathrm{Cr}^{3+}$ controls the $\mathrm{pH}$ inside the pit or crevice due to the lower solubility of the chromium hydroxides ${ }^{3}$. Assuming congruent dissolution ${ }^{4}$, this would limit the maximum $\mathrm{Cr}$ concentration to around $1 \mathrm{M}$ at the onset of $\mathrm{FeCl}_{2}$ precipitation, yielding a theoretical $\mathrm{pH}$ of 1.53 ${ }^{3,4}$ when adopting an activity coefficient of protons, $\gamma_{H_{+}}$, of 1 . However, the $\mathrm{pH}$ of solutions sampled from inside actively dissolving artificial pits was on the order of $0^{4}$, i.e. well below the theoretical limit. This discrepancy has been explained based on the effect of the high concentration of chloride ions on $\gamma_{\mathrm{H}+}{ }^{4,5}$.

The work by Suzuki et al. suggests that a $1 \mathrm{~N}$ hydrochloric acid $(\mathrm{HCl})$ solution is a reasonable choice to simulate a pit or crevice environment for stainless steels containing $18 \mathrm{wt} . \% \mathrm{Cr}^{4}$. Galvele et al. ${ }^{2}$ used $1 \mathrm{~N} \mathrm{HCl}$ to estimate the critical potential of $\mathrm{Fe}-18 \% \mathrm{Cr}$ steels with varying amounts of molybdenum. However, later studies concluded that both local acidification and a much larger concentration of chloride ions contribute to stabilizing pit growth and prevent passivation ${ }^{6}$. The maximum chloride concentration inside pits is also limited by precipitation of the corresponding metal cation salt. In stainless steels, experimental values of the chloride concentration of the solution inside either artificial or real pits of approximately $6 \mathrm{M}^{4}$ and $12 \mathrm{M}^{5} \mathrm{Cl}^{-}$ have been reported, respectively. The $\mathrm{pH}$ of iron chloride and chromium chloride solutions, similar to those existing inside pits, was a strong function of the chloride concentration ${ }^{5}$.

Bocher et al. $^{7}$ presented a detailed method to prepare a simulated pitlike solution for many $\mathrm{Ni}$ - or Fe-base corrosion resistant alloy (CRA). In this method, the two major assumptions were the congruent dissolution of the alloying elements and that the acidity of the solution is determined mainly by the chromium hydrolysis reaction, both reasonable assumptions based on previous evidence ${ }^{3,4}$. In their work, the maximum concentration of chloride in the pit- or crevice-like 
solution was limited by precipitation of a salt film. A salt film of the major alloying element precipitates when its solubility limit is reached ${ }^{7}$. Therefore, for a stainless steel at room temperature, a $\mathrm{FeCl}_{2}$ film would precipitate when the concentration of $\mathrm{Fe}^{2+}$ reaches $4.38 \mathrm{M}^{8}$. According to Bocher ${ }^{7}$, the chloride concentration in the saturated pit-like solution can be calculated as:

$$
\left[\mathrm{Cl}^{-}\right]=2\left[\mathrm{Fe}^{2+}\right]+2\left[\mathrm{Ni}^{2+}\right]+3\left[\mathrm{Cr}^{3+}\right]+3\left[\mathrm{Mo}^{3+}\right]
$$

The concentration of the major alloying element is given by the solubility of the corresponding chloride salt while the concentration of the remaining alloying elements is determined assuming congruent dissolution. Likewise, the $\mathrm{pH}$ of the pit-like solution depends on the chromium concentration in the solution inside the pit. In Bocher et $a l^{7}$, the equation that relates $\mathrm{pH}$ with $\left[\mathrm{Cr}^{3+}\right]$ is based on the empirical fitting presented by Oldfield and Sutton ${ }^{3}$, using data by Mankowski and Szklarska-Smialowska ${ }^{5}$. Application of this approach to UNS N06625 yielded a total chloride concentration of $12.87 \mathrm{M}$ and a $\mathrm{pH}$ equivalent to $0.1 \mathrm{M} \mathrm{HCl}^{7}$. Simulated pit solutions were prepared with $\mathrm{LiCl}$ rather than metal chlorides of the main alloying elements, to prevent any redox reactions of the metal cations that could complicate the interpretation of the polarization curves. $\mathrm{LiCl}$ has a solubility limit of $14.01 \mathrm{M}$ at $25^{\circ} \mathrm{C}^{8}$, higher than the rest of common alkaline or alkalineearth chlorides. Therefore, its use allowed achieving the chloride concentrations required to simulate pit-like solutions.

Applying the Bocher et al. ${ }^{7}$ methodology to duplex and super duplex stainless steels (DSS and SDSS, respectively) yields chloride concentrations larger than the solubility limit of LiCl. Furthermore, the method to prepare pit-like solutions as described by Bocher et al. ${ }^{7}$ does not take into account the common ion effect; that is, the solubility of a metal chloride could be lowered in the presence of other metal chlorides. On the other hand, the formation of $\mathrm{Cr}^{3+}$ chlorocomplexes could weaken or eliminate the common ion effect ${ }^{9}$.

Last, it is still unresolved whether metal salt precipitation is required for stable crevice or pit propagation. Some studies ${ }^{10-12}$ suggest that stable pits do not necessarily grow in a saturated metal chloride solution. Values as low as $50 \%$ of saturation in $\mathrm{FeCl}_{2}$ were reported for stainless steels. Bocher et al. ${ }^{7}$ dealt with these uncertainties preparing several dilutions of the solution saturated in metal chlorides, but there is no clear procedure to choose the best composition to simulate the pit or crevice environment. Considering that crevices should be equivalent to large pits ${ }^{1,13}$, it can be added that the chloride concentration reached a maximum at $0.4 \mathrm{~mm}$ in pit diameter. For larger pits concentrations ranging from 2 to $5 \mathrm{M} \mathrm{Cl}^{-}$were reported ${ }^{5}$, well below the saturation limit of $\mathrm{FeCl}_{2}^{8}$.

The larger size of crevices, when compared to pits, has allowed in situ measurements of potential, $\mathrm{pH}$, and chloride content, as reviewed by Turnbull $^{14}$. Sridhar and Dunn ${ }^{13}$ measured changes in potential, chloride concentration, and $\mathrm{pH}$ with microelectrodes placed inside a rectangular crevice of either UNS S30403 (AISI Type 304L) stainless steel or nickel alloy 825 (UNS N08825) and polymethyl methacrylate. The measured changes in $\mathrm{pH}$ were a function of the metal, the surface roughness (as it affects the crevice gap) and the composition of the environment. Changes in $\mathrm{pH}$ between bulk and crevice solution were modest in comparisons to the results previously presented for pits. For example, a pH of 3 in the crevice region was measured for UNS N08825 exposed to an external $\mathrm{pH}$ of 8.5. The chloride concentration increased from $0.028 \mathrm{M} \mathrm{NaCl}$ in the bulk to $0.14 \mathrm{M}$ at the tip of the crevice. The authors ${ }^{13}$ discussed how formation of chloro-complexes could result in a greater concentration of $\mathrm{Cl}^{-}$in the crevice because $\mathrm{AgCl}$ microelectrodes could only sense free $\mathrm{Cl}^{-}$. Other authors ${ }^{15}$ also reported that there was no increase in chloride concentration during crevice corrosion initiation using the same type of sensor.

In situ techniques based on $\mathrm{pH}$ and $\mathrm{Cl}^{-}$sensing plates were used to characterize $\mathrm{pH}$ and $\mathrm{Cl}^{-}$concentration changes in artificial crevices in stainless steels ${ }^{16}$. Similarly to Sridhar and Dunn, no increase in chloride concentration was detected initially, but the $\mathrm{pH}$ dropped gradually to 1.7, from a bulk value of 3 , during the incubation time. At this point, a pit nucleated in the crevice region, causing a further sharp local drop in $\mathrm{pH}$ to 0.40 and a sharp local increase in chloride concentration to 4.0 $\mathrm{M} \mathrm{NaCl}$ (from a bulk value of 0.01 ). The pit nucleation time, which determines the starting point of crevice corrosion propagation, could not be assessed based on the current signal ${ }^{16}$. In contrast, Sridhar and Dunn were able to correlate the current signal with crevice corrosion initiation and propagation. Similar to pitting, there are quantitative uncertainties related to the local concentration of chloride and $\mathrm{pH}$ at the onset of crevice corrosion initiation.

Although Galvele's model provides a methodology to estimate critical potentials leading to either stable pitting or crevice corrosion, limited work has been done to verify the validity of the model using engineering alloys. The objective of this work was, therefore, to apply Galvele's model to predict the localized corrosion behavior of a duplex and a super duplex stainless steel in seawater exposure.

\section{EXPERIMENTAL}

UNS S32750 and UNS S31803 samples were received in the solution annealed condition. Annealing temperatures and times were $1100^{\circ} \mathrm{C}$ for 30 minutes for UNS $S 32750$ and $1060^{\circ} \mathrm{C}$ for 150 minutes for UNS S31803, followed by water quenching in both cases. Table 1 summarizes the chemical composition of both alloys used in this investigation.

Samples were ground to 600 grit SiC paper and cleaned with deionized water and ethanol. All experiments presented here were performed in duplicate at a minimum. All tests were conducted at room temperature, recognizing that both $\mathrm{NORSOK}^{\left({ }^{1)}\right.}$ standard $\mathrm{M}-001^{17}$ and ISO $^{(2)} 21457^{18}$ impose a $20^{\circ} \mathrm{C}$ maximum operating temperature limit for SDSS exposed to seawater.

\section{Potentiodynamic polarization in simulated seawater}

Cyclic potentiodynamic polarization (CPP) curves were measured in 3.5 wt.\% $\mathrm{NaCl}$ prepared with reagent grade chemicals and deaerated with nitrogen at room temperature. Samples had an exposed area of approximately $2 \mathrm{~cm}^{2}$ and were suspended using a $200 \mu \mathrm{m}$ diameter platinum wire, which was connected to the potentiostat. The metal was partially immersed to prevent any form of undesired crevice or galvanic corrosion. No preferential corrosion at the waterline was observed in the alloys studied in this work. The open circuit potential $\left(E_{\mathrm{OC}}\right)$ was measured for 1 hour before conducting polarization experiments. A cyclic polarization experiment was conducted starting from a potential $20 \mathrm{mV}$ below the $\mathrm{E}_{\mathrm{OC}}$ up to an anodic current density of $10 \mathrm{~mA} / \mathrm{cm}^{2}$, at this point, the potential scan direction was reversed. The experiment ended after reaching a cathodic current. Additionally, two different potential scanning rates, $0.167 \mathrm{mV} / \mathrm{s}$ and $0.0167 \mathrm{mV} / \mathrm{s}$, were used to investigate the effect of potential scan rate on pitting and repassivation potentials.

(1) NORSOK Standards Norway, Strandveien 18, N-1326 Lysaker, Norway.

(2) International Organization for Standardization (ISO), Chemin de Blandonnet 8, CP 401, 1214 Vernier, Geneva, Switzerland. 


\section{Potentiodynamic polarization in pit-like solutions}

Potentiodynamic polarization curves were measured in solutions that simulated those present inside pits and crevices at room temperature. Given the conflicting evidence discussed above, five different crevicelike solutions were prepared: i) $1 \mathrm{M} \mathrm{HCl}$, ii) $5 \mathrm{M} \mathrm{NaCl}$, iii) $3.5 \mathrm{M} \mathrm{CaCl}_{2}$, iii) $9 \mathrm{M} \mathrm{LiCl}$ and iv) $12 \mathrm{M} \mathrm{LiCl}$. The $\mathrm{pH}$ of each solution was adjusted with $\mathrm{HCl}$ to a $\mathrm{pH}$ of 0 . The $12 \mathrm{M} \mathrm{LiCl}$ solution had a chloride concentration close to that present inside a pit or crevice saturated with metal chlorides $^{3,5,7}$. The solution with $9 \mathrm{M} \mathrm{LiCl}, 3.5 \mathrm{M} \mathrm{CaCl}_{2}$, and $5 \mathrm{M} \mathrm{NaCl}$ represent chloride concentrations of $75 \%, 58 \%$ and $42 \%$ of the saturated chloride pit solution, respectively. Tests in $1 \mathrm{M} \mathrm{HCl}$ were included to characterize the behavior of stainless steels at $\mathrm{pH} 0$ in the absence of additional chlorides. The target amount of $\mathrm{HCl}$ needed to reach $\mathrm{pH} 0$ is a function of chloride concentration in the solution and was calculated following the procedure detailed by Bocher et al. ${ }^{7}$

Samples were mounted in cold setting epoxy and exposed to the deaerated solutions. Before anodic polarization, samples were left at the $\mathrm{E}_{\mathrm{OC}}{ }^{*}$ for 1 hour; the star sign indicates that the potential was measured in a simulated crevice solution. The scan rate was set to $0.167 \mathrm{mV} / \mathrm{s}$ for those experiments. No preferential attack near the boundary of the exposed metal and the epoxy was observed in any case.

\section{Crevice corrosion tests in simulated seawater}

Crevice corrosion in $3.5 \mathrm{wt} . \% \mathrm{NaCl}$ was studied using the Potentiodynamic-Galvanostatic-Potentiodynamic (PD-GS-PD) technique ${ }^{19}$. The method involved creviced specimens fabricated based on ASTM ${ }^{(3)}$ standards G-192 and G-48, which contained 24 artificially creviced spots formed by two ceramic washers (crevice formers) wrapped with a $70 \mu \mathrm{m}$-thick Polytetrafluoroethylene (PTFE) tape. The crevice formers were fixed to the sample with a titanium-made nut and bolt system, tightened to a torque of $5 \mathrm{~N}-\mathrm{m}^{20}$. The surface areas exposed to the solution were approximately $12 \mathrm{~cm}^{2}$. Samples were mechanically ground to 600 grit $\mathrm{SiC}$ paper and rinsed with deionized water and ethanol prior to electrochemical tests. Before starting the crevice corrosion experiment, $\mathrm{E}_{\mathrm{OC}}$ was measured for 15 minutes. Subsequently, a galvanostatic cathodic current of $1 \mu \mathrm{A} / \mathrm{cm}^{2}$ was applied for 15 minutes to reduce surface oxides.

The PD-GS-PD method consisted of three stages: (1) a potentiodynamic polarization (at a scan rate of $0.167 \mathrm{mV} / \mathrm{s}$ ) from $\mathrm{E}_{\mathrm{OC}}$ in the anodic direction until attaining an anodic current of $300 \mu \mathrm{A} ;(2)$ the application of a constant anodic current of $\mathrm{I}_{\mathrm{GS}}=300 \mu \mathrm{A}$ (approximately $\mathrm{i}_{\mathrm{GS}}=25 \mu \mathrm{A} / \mathrm{cm}^{2}$ ) for 2 hours; and (3) a potentiodynamic polarization (at $0.167 \mathrm{mV} / \mathrm{s}$ ) in the cathodic direction, from the previous potential until alloy repassivation. Three replicates were performed for each testing condition on each alloy. The crevice corrosion repassivation ${ }^{19}$ potential was defined as the cross-over potential $\left(\mathrm{E}_{\mathrm{co}}\right)$ determined at the intersection of the forward (stage 1 ) and reverse (stage 3 ) scans. Crevice corrosion was corroborated with observation in the optical microscope. More details of this experimental technique can be found elsewhere $^{19,21}$.

\section{RESULTS AND DISCUSSION}

\section{Polarization curves in simulated seawater}

Figure 1 shows the polarization behavior of UNS S32750 and UNS S31803 stainless steel measured in deaerated $3.5 \mathrm{wt} . \% \mathrm{NaCl}$ solution. Both alloys exhibited a similar passive current density and a

${ }^{(3)}$ ASTM International (ASTM), 100 Barr Harbor Drive, West Conshohocken, PA 19428-2959 breakdown of the passive film at a potential close to $1 \mathrm{~V}_{\mathrm{SCE}}(1.241$ $\left.\mathrm{V}_{\mathrm{NHE}}\right)$. This potential was above the oxygen evolution potential at $\mathrm{pH}$ 7.0 and the chromium oxide dissolution potential ${ }^{22}$. Change in solution color suggesting dissolution of the chromium oxide and evolution of oxygen bubbles at this point were seen in all cases. At the end of the experiment, samples presented evidence of pit growth. A 10X decrease in potential scanning rate resulted in a decrease in passive current density of almost one order of magnitude and a slight drop in breakdown potential of around $30 \mathrm{mV}$ for both alloys, Figure $1 \mathrm{~b}$.

All cyclic polarization scans showed positive hysteresis, in accord with the presence of pits observed at the end of the experiments. The repassivation potential decreased slightly with scanning rate. A decrease in ERP is a function of the depth of the pits that developed in the forward scan ${ }^{1,23,24}$. Pitting potentials and repassivation potentials measured at room temperature were close to the transpassive dissolution potential for both alloys, as expected considering that the test temperature was below the critical pitting temperatures (CPT) ${ }^{25}$. CPT for alloys with a composition similar to that of UNS S32750 and UNS S31803 are around $65^{\circ} \mathrm{C}$ and $30^{\circ} \mathrm{C}$, respectively ${ }^{26,27}$.

\section{Polarization curves in crevice-like solutions}

Polarization curves measured in crevice-like solutions are shown in Figure 2. A major limitation associated with the use of bulk prepared crevice-like solutions is that they cannot simulate the concentration gradients that exist in real pits or crevices ${ }^{6}$. It can be seen that corrosion potentials of both alloys were between $-0.350 \mathrm{~V}_{\mathrm{SCE}}$ and $-0.300 V_{S C E}$ in all cases independently of the composition of the crevicelike solution. This result is in accord with those presented by Sridhar and Cragnolino ${ }^{28}$, where the corrosion potential of UNS N08825 in simulated pit solutions was independent of chloride content but a strong function of $\mathrm{pH}$, as the hydrogen reduction reaction is the dominant cathodic reaction in a deaerated electrolyte at $\mathrm{pH}=0$.

Both alloys exhibited an active-to-passive behavior in $1 \mathrm{M} \mathrm{HCl}$, followed by transpassive dissolution at higher potentials. The critical current to reach passivation, $\mathrm{i}_{\text {Flade }}$, was lower for UNS S32750 than for UNS S31803, which was in accord with the higher content of $\mathrm{Cr}^{29,30}$, $\mathrm{N}^{31}$ and possibly the presence of $\mathrm{W}^{32,33}$. Those alloying elements could also be responsible for the lower Flade potential of the SDSS. Transpassive dissolution and oxygen evolution were observed at a lower potential than in the $3.5 \mathrm{wt} . \% \mathrm{NaCl}$ solution, (Figure 1). Visual examination after removing the samples from solution revealed an etched surface with shallow pits.

Polarization curves in $5 \mathrm{M} \mathrm{NaCl}$ acidified to $\mathrm{pH} 0$ exhibited a larger $\mathrm{i}_{\text {Flade }}$ than those in $1 \mathrm{M} \mathrm{HCl}$, which was expected based on the higher chloride content of the solution ${ }^{5}$. The $\mathrm{i}_{\text {Flade }}$ of UNS S31803 almost doubled that of UNS S32750. The higher alloyed stainless steel also exhibited a wider passive zone and a lower passive current density.

The most significant difference between both alloys was observed in the $7 \mathrm{~N} \mathrm{Cl}^{-}$solution at $\mathrm{pH} 0$. The $\mathrm{i}_{\text {Flade }}$ of UNS S31803 was one order of magnitude greater than that of UNS S32750. The passive current density was also one order of magnitude higher for UNS S31803. Some authors suggested that approximately $7 \mathrm{~N} \mathrm{Cl}^{-}$should be around the minimum chloride ion concentration required to stabilize localized corrosion of stainless steels ${ }^{11}$.

The shape of the polarization curves in $9 \mathrm{M} \mathrm{LiCl}$ and $12 \mathrm{M} \mathrm{LiCl}$ acidified to $\mathrm{pH} 0$ suggested that, under these conditions, a metal salt film precipitated during anodic polarization ${ }^{29,34}$. Initially, current density increased until the local metal chloride concentration close to the sample reached the supersaturation required for salt film 
precipitation $^{34}$, which was followed by a sharp decrease in current and a subsequent stabilization of current density at a constant value. A simple 1-D steady state diffusion model yields that the current density under diffusion control is given by:

$$
i_{\text {lim }}=\frac{n F D C_{s a t}}{\delta}
$$

where $\mathrm{n}$ is the number of electrons exchanged in the metal oxidation reaction in eq/mol, $\mathrm{F}$ is the Faraday constant in $\mathrm{C} / \mathrm{eq}, \mathrm{D}$ is the diffusion coefficient in the solution of the metal cation in $\mathrm{cm}^{2} / \mathrm{s}, \mathrm{C}_{\text {sat }}$ is the saturation concentration of the metal cation in the solution in $\mathrm{mol} / \mathrm{cm}^{3}$ and $\delta$ is the diffusion layer thickness in $\mathrm{cm} . \mathrm{C}_{\text {sat }}$ depends on the chloride concentration of the solution, assuming iron(II) chloride precipitation and approximating activities by concentrations:

$$
\mathrm{C}_{\text {sat }}=\frac{\mathrm{k}_{\mathrm{ps}}^{\mathrm{FeCl}_{2}}}{\left[\mathrm{Cl}^{-}\right]^{2}}
$$

where $k_{p s}$ is the solubility product of iron(II) chloride. Under the assumption that the diffusion coefficient and diffusion layer thickness are independent of chloride concentration, the following equation could be used to estimate the ratio of limiting current densities at the two different chloride concentrations:

$$
\frac{i_{l i m}^{\left[C l^{-}\right]=9 M}}{i_{l i m}^{\left[C l^{-}\right]=12 M}}=\frac{12^{2}}{9^{2}} \simeq 1.78
$$

Table 2 presents the diffusion limited current densities of both alloys at both chloride concentrations. The error between the expected and experimental current ratio was $4 \%$ and $28 \%$ for UNS 532750 and UNS $\mathrm{S} 31803$, respectively. A source of error in these calculations is the dependence of $D$ and $\delta$ in Eq. 1 on the chloride content and the viscosity of the solutions. On the other hand, the saturation concentration of iron chloride(II) could also be affected by the local concentration of other cations. Despite the error in the ratio of limiting currents, the shape of the curves suggests that for those two chloride concentrations, dissolution of the steels was under diffusion control at a certain potential range.

UNS S32750 and UNS S31803 polarization curves exhibited a similar behavior in $9 \mathrm{M} \mathrm{LiCl}$ and $12 \mathrm{M} \mathrm{LiCl}$ from the open circuit potential up to the diffusion limited current density zone. However, UNS S32750 passivated after precipitation of a salt film in both environments, whereas UNS S31803 did not passivate after precipitation of the salt film in the $12 \mathrm{M} \mathrm{LiCl}$ environment. Grimm and Landolt ${ }^{29}$ presented potentiodynamic polarization curves of pure iron, $15 \mathrm{Cr}-\mathrm{Fe}, 25 \mathrm{Cr}$-Fe and pure $\mathrm{Cr}$ in $4 \mathrm{M} \mathrm{FeCl}_{2}$ and $5 \mathrm{M} \mathrm{NaCl}$. All Fe-containing alloys presented active dissolution followed by salt film precipitation and transpassive dissolution, whereas pure $\mathrm{Cr}$ exhibited passive behavior followed by transpassive dissolution. Therefore, the passivation after salt film precipitation observed in this work was probably related to the other alloying elements such as Mo, N, W, and Cu present in the stainless steels.

Bocher et al. ${ }^{7}$ studied the polarization behavior of $\mathrm{Ni}-\mathrm{Cr}$-Mo alloys in a $12.87 \mathrm{M} \mathrm{LiCl}$ solution with a $\mathrm{pH}$ of 1.0 at room temperature and determined that a Mo content of $13 \mathrm{wt} . \%$ was required for passivation after salt film formation. It is notable that with only $3.3 \mathrm{wt} . \%$ Mo UNS S32750 could passivate at high potentials in a $12 \mathrm{M} \mathrm{LiCl}$ solution. What is even more surprising is the difference between both alloys studied here despite their very similar molybdenum content. As discussed before, this difference cannot be explained in terms of $\mathrm{Cr}$ content alone due to the fact that Fe-Cr alloys do not passivate after salt film formation ${ }^{29}$. One alloying element that could promote passivation is $\mathrm{W}$, present in the SDSS ${ }^{33}$. W oxides are stable at low $\mathrm{pH}$ and are not expected to dissolve at a high potential in acid environments ${ }^{22}$; however, whether $\mathrm{W}$ promotes passivity by forming $\mathrm{WO}_{3}$ or facilitates repassivation once dissolved as $\mathrm{WO}_{4}{ }^{2-}$ is still unclear ${ }^{32,33,35,36}$. Copper ${ }^{37}$ has also been reported to increase pitting potentials and critical pitting temperatures in both acid and neutral chloride environments, and to reduce $\mathrm{i}_{\text {Flade }}$ in a $1 \mathrm{~N} \mathrm{HCl}$ solution.

In addition to $\mathrm{W}$ and $\mathrm{Cu}$, UNS S32750 had a higher $\mathrm{N}$ content than the UNS S31803 used in this investigation. $\mathrm{N}$ is expected to have a higher concentration in the austenite phase. For austenitic UNS S31600 stainless steels, the inhibiting effect of $\mathrm{N}$ in concentrated $\mathrm{HCl}$ solutions is observed at high $\left(>1 \mathrm{~A} / \mathrm{cm}^{2}\right)$ currents and under active dissolution of the steel ${ }^{10,31}$. The enhanced passivation after salt film formation observed here for the UNS S32750 alloy has not been seen in other systematic studies of the effect of $\mathrm{N}$ in steels ${ }^{31,38}$, but cannot be discarded $a$ priori as a possible reason for the difference in response between UNS S32750 and UNS S31803.

Figure 3 summarizes the maximum current densities measured previous to passivation or salt film formation for both alloys as a function of chloride concentration. Similar to what has been shown elsewhere for austenitic stainless steels ${ }^{31}$, it can be observed that $\mathrm{i}_{\text {Flade }}$ increased with chloride concentration, and the current density for salt film precipitation decreased with increased chloride concentration, as predicted by the 1-D steady-state diffusion model presented above, Eq. 1-3. The maximum current in this graph occurred at the most "aggressive" crevice-like solution, that is, the solution where the maximum anodic current density could be sustained. It is seen that the most aggressive solution for UNS S31803 and UNS S32750 should be close to $7 \mathrm{~N} \mathrm{Cl}^{-}$and $9 \mathrm{~N} \mathrm{Cl}^{-}$, respectively. Alloying elements like $\mathrm{Cr}^{29,30}$, $\mathrm{N}^{31}$, and $\mathrm{W}^{32,33,39,40}$, present in higher amount in the UNS S32750 than in the UNS S31803 alloy could have been responsible for the lower passivation currents measured in the former alloy. The maximum current prior to salt film formation was a function of bulk chloride content of the solution and potential scan rate ${ }^{31}$, but it was remarkably similar for both stainless steels at a given potential scan rate.

\section{Prediction of crevice corrosion potential}

Galvele's equation ${ }^{1}$ can be used to estimate the critical localized corrosion potentials, $\mathrm{E}_{\text {crit }}$ :

$$
E_{\text {crit }}=\mathrm{E}_{\mathrm{OC}}{ }^{*}+\eta+\Phi+E_{\text {inh }}
$$

where $\mathrm{E}_{\mathrm{OC}}{ }^{*}$ is the corrosion potential of the metal/alloy in the solution inside the pit or crevice, $\eta$ is the anodic polarization required to reach a critical current $i_{\text {crit }}$ at the bottom of a pit or crevice, $\Phi$ is the ohmic potential drop along the pit or crevice, and $\mathrm{E}_{\text {inh }}$ is an additional polarization required in the presence of buffers or inhibitors. Although the dissolution of molybdenum, tungsten, and nitrogen into the pit or crevice environment could lead to the formation of inhibiting species such as molybdates ${ }^{35,39,41}$, tungstates ${ }^{35,39,41}$, and possibly $\mathrm{NH}_{4}{ }^{+39}$, the contribution of $E_{i n n}$ to $E_{c r i t}$ is ignored herein. This simplification of the model can be sustained as it yields more conservative, i.e. lower, $E_{\text {crit }}$ values. The critical current, $i_{\text {crit, }}$, relates to a characteristic depth $x$ of the pit or crevice. In this regard, $i_{\text {crit }}$ is the minimum current required to maintain an acid environment inside the pit, resulting from hydrolysis of metal cations. Diffusion of metal cations to the outside of the pit results in a dependence of critical current with pit depth. According to Galvele's mechanism, pits and crevices can be dealt with the same approach, the only difference being the magnitude of the diffusion path, $x$. Given that Galvele proposed a theoretical unidimensional 
construction to describe pits and crevices, no mention of the crevice mouth opening gap is given in the original paper. The critical current is a function of the diffusion distance, and it follows the relation:

$$
x \cdot i_{\text {crit }}=k
$$

where $\mathrm{k}$ is a constant that is a function of the metal and bulk $\mathrm{pH}^{1,42}$.

Figure 2 shows that for any choice of crevice-like solution or alloy, the $\mathrm{E}_{\mathrm{OC}}{ }^{*}$ term was between -0.350 and $-0.300 \mathrm{~V}_{\text {SCE }}$. To estimate the overpotential term, suitable values for the depth of the crevice and $k$ are required. In this work, we adopted $x=10^{-4} \mathrm{~cm}$ and $k=10^{-6} \mathrm{~A} / \mathrm{cm}$ as a first approximation as suggested by Galvele in a later publication ${ }^{43}$. According to these constants, the critical current needed to maintain the acidic environment within the crevice is $i_{\text {crit }}=10^{-2} \mathrm{~A} / \mathrm{cm}^{2}$. Such value of current density was only attained in solutions with [ $\left.\mathrm{Cl}^{-}\right]$above $7 \mathrm{M}$ (Figure 2 and Figure 3). Table 3 summarizes the calculated crevice corrosion potentials for both alloys.

The ohmic potential drop term, $\Phi$, was estimated based on the following equation ${ }^{7,44}$ :

$$
\Phi=\frac{\rho i_{c r i t} \mathrm{x}^{2}}{2 w}
$$

and assuming a resistivity, $\rho$, of $10 \Omega . c m$ and a crevice gap, w, of $1 \mu \mathrm{m}^{7}$. While the resistivity of the solution in the pit model should depend on the actual ion concentration inside the crevice, the value assumed here is an "effective resistivity" that incorporates some effects of tortuosity and debris, as proposed by Bocher et $a l^{7}$. The calculated ohmic potential drop term was around $5 \mu \mathrm{V}$, several orders of magnitude lower that the rest of the contributions to the critical potential (Table 3). The low ohmic potential drop contrasted with results previously presented by Shaw et al. ${ }^{44}$ and Bocher et al. ${ }^{7}$, where $\Phi$ was $300 \mathrm{mV}$ and $500 \mathrm{mV}$, respectively.

The main difference with respect to the calculations by Shaw et al. ${ }^{44}$ is that they assumed a much larger value for $x$, i.e. $1 \mathrm{~cm}$, well above the dimensions of the crevice former teeth used here. In this study, crevice corrosion initiated near the edge of the crevice former, as shown in the inset in Figure 4 (right) for the DSS. Likewise, the authors assumed that the current flowing from the crevice was equal to the passive current density, on the order of $10^{-6} \mathrm{~A} / \mathrm{cm}^{2}$ and the crevice gap value adopted was $0.1 \mu \mathrm{m}$. Bocher et al. ${ }^{7}$ assumed a much larger critical value for the $x . i_{\text {crit }}$ product, namely, $0.01 \mathrm{~A} / \mathrm{cm}$. This value chosen for $k$ is based on previous results of the i.r limit (where $r$ is the radius of a hemispherical pit) that separates metastable pits from stable pits in stainless steels ${ }^{12,39,45,46}$. At this value of $x . i_{\text {crit, }}$ the solution inside the pit is at or near the range of salt film precipitation ${ }^{12}$. Galvele's mechanism does not detail the events before attaining a critical $x . i_{\text {crit }}$, the main focus is the onset of stable localized corrosion growth. Similarly, in this work, the mechanisms of crevice corrosion initiation were not the main focus. Nevertheless, according to one of such mechanisms ${ }^{47}$, metastable pits of a smaller size can survive cover rupture events if nucleated inside crevices, as they are stabilized by the crevice geometry. Therefore, we opted to use the much lower value of $x \cdot i_{c r i t}=$ $10^{-6} \mathrm{~A} / \mathrm{cm}$, suggested by Galvele in one of his latest publications ${ }^{43}$. The validity of these choices is further discussed below.

\section{Consequences of the choice of constants}

The discussion of the last paragraph introduced the issue of the selection of constants for the application of Galvele's model. In this regard, Galvele's initial publications dealt with pure metals ${ }^{1,42,48}$ Dramatically different conclusions can be reached depending on the choice of those values. Had values proposed by Bocher et al. ${ }^{7}$ been adopted in the calculation, i.e. $x . i_{\text {crit }}=0.01 \mathrm{~A} / \mathrm{cm}$ and $x=10^{-3} \mathrm{~cm}$, then, $a$ critical current density $i_{\text {crit }}=10 \mathrm{~A} / \mathrm{cm}^{2}$ would have been calculated. Figures 2 and 3 show that such a high current density can only be attained at values well beyond the transpassive potential, for any given choice of crevice-like solution. An $\mathrm{i}_{\text {Crit }}$ of $10 \mathrm{~A} / \mathrm{cm}^{2}$ is also more than one order of magnitude above anodic current density values reported for stable pit growth on stainless steels, which were in the 0.3 to 1.1 $\mathrm{A} / \mathrm{cm}^{2}$ range $\mathrm{e}^{2,49}$. Considering stainless steels would be unlikely to reach such high potential values in service, Galvele's model would have predicted that both DSS and SDSS were immune to crevice corrosion at room temperature, a result that contradicts service and laboratory experience with UNS S31803 ${ }^{50-52}$ and UNS S32750 stainless steels ${ }^{20,53}$. Similarly, crevice corrosion studies of nickel-based alloys also concluded that a value of $x . i_{\text {crit }}=0.01 \mathrm{~A} / \mathrm{cm}$ would lead to unrealistic predictions ${ }^{54}$.

\section{Comparison of predicted versus measured critical crevice corrosion potentials in nearly neutral chloride solutions}

Martinez et al. ${ }^{20}$ recently reported crevice repassivation potentials and crevice protection potentials of $25 \mathrm{Cr}$ SDSS measured by the Potentiodynamic-Galvanostatic-Potentiodynamic (PD-GS-PD) and Potentiodynamic-Potentiostatic-Potentiodynamic (PD-PS-PD) methods. The repassivation potential measured by the PD-GS-PD method was $-0.200 \mathrm{~V}_{\mathrm{SCE}}$, and it did not have a clear dependence on either chloride content or temperature, measured in 10,000 and 100,000 ppm chloride solutions (equivalent to 1.65 and $16.5 \mathrm{wt} . \% \mathrm{NaCl}$, respectively) at 30,60 and $90^{\circ} \mathrm{C}$. Galvele's model ${ }^{1}$ predicts that bulk chloride content affects the critical potential primarily due to the effect on the ohmic drop term. Based on the choice of constants previously discussed, it was concluded that ohmic drop had a negligible contribution to the critical crevice potential, which explains why a similar critical potential was obtained ${ }^{20}$ in two solutions with different chloride concentrations.

A crevice protection potential range was defined as the potential range limited by the maximum potential in the PS step that resulted in no crevice corrosion after a $20 \mathrm{~h}$ potentiostatic polarization and the minimum potential in the PS step that caused crevice corrosion propagation during the same period ${ }^{20}$. For $25 \mathrm{Cr}$ SDSS samples of similar composition to the one studied here, the authors estimated a protection potential range between -0.150 and $-0.100 \mathrm{~V}_{\text {SCE }}$ in 10,000 ppm chloride solutions at $30^{\circ} \mathrm{C}$ (equivalent to $1.65 \mathrm{wt} . \% \mathrm{NaCl}$ ). These values are in reasonable accord with the ones shown in Table 3.

Figure 4 shows results obtained in this work by the PD-GS-PD method on UNS S31803 duplex stainless steel at room temperature. Three independent measurements were performed. The average $\mathrm{E}_{\mathrm{CO}}$ was $-0.181 \pm 0.034 \mathrm{~V}_{\text {SCE}}$, where the error was estimated by the standard deviation. Similar to the results obtained by Martinez et al. ${ }^{20}$ for $25 \mathrm{Cr}$ SDSS, in the forward scan the potential had to reach a value near the transpassive potential to reach the current required for the galvanostatic step (Figure 4, left). The potential dropped considerably during the GS step (Figure 4, right), and observations in the microscope at the end of the experiment revealed the presence of crevice corrosion. Based on similar results on $25 \mathrm{Cr}$ SDSS, it is expected that crevice corrosion should initiate if the sample were polarized close to the $E_{C O}$ potential during $20 \mathrm{~h}^{20}$. Furthermore, for the corrosion resistant nickel base alloy UNS N06022 Rincon Ortiz et al. ${ }^{21}$ showed that the crevice repassivation potential measured with the PD-GS-PD method should be close (within $30 \mathrm{mV}$ ) to the protection potential, that is, the minimum potential required for crevice corrosion initiation. The $\mathrm{E}_{\mathrm{CO}}$ value obtained experimentally with the PD-GS-PD method was close, i.e. within $20 \mathrm{mV}$, to the predictions made using Galvele's model. 


\section{Comparison with open circuit potentials in seawater}

In service, crevice corrosion requires a demanding crevice, a cathodic reaction that supports the required current for the dissolution of the metal in the occluded area, and a corrosion potential above the critical crevice potential ${ }^{44,55}$. A demanding crevice is a tight crevice formed between the metal and a non-porous material, which can be a similar or a dissimilar metal, a ceramic, or a polymer ${ }^{55}$. Typical examples of crevice forming situations are threaded connections, flanged connections, and gaskets ${ }^{51}$. Reduction of oxygen over the non-creviced passivated metal surface is the main cathodic reaction for stainless steels exposed to seawater ${ }^{44}$. Steady state corrosion potentials in simulated seawater reported in the literature for UNS S31803 and UNS S32750 are between $0.025 \mathrm{~V}_{\text {SCE }}$ and $-0.125 \mathrm{~V}_{\mathrm{SCE}}{ }^{56}$, respectively. Those values are above the critical crevice potentials found here for both materials, suggesting the alloys might be susceptible to crevice corrosion in natural seawater at room temperature. Furthermore, in natural seawater the formation of a biofilm on the surface of the metal could result in a further increase in open circuit potential to values around 0.300 to $0.400 \mathrm{~V}_{\mathrm{SCE}}{ }^{44,57}$. Use of chlorination to control microbial activity can further raise $\mathrm{E}_{\mathrm{OC}}$ to 0.500 to $0.650 \mathrm{~V}_{\text {SCE, }}$ depending on the chlorination level ${ }^{57}$. The susceptibility to crevice corrosion in seawater service predicted here for both stainless steels is in accordance with the limits imposed by NORSOK M-001 and ISO 21457 standards on the maximum allowable service temperature for seawater service. The standards impose an upper limit of $20^{\circ} \mathrm{C}$ to $25 \mathrm{Cr}$ SDSS while prohibiting the use of $22 \mathrm{Cr}$ DSS. The standards are based on reports of crevice corrosion failures in service. Cases of crevice corrosion failures of duplex stainless steels in seawater at room temperature have been discussed in the literature ${ }^{50,51,58}$.

\section{CONCLUSIONS}

* Galvele's model correctly predicted the occurrence of crevice corrosion of both UNS S32750 super duplex stainless steel and UNS S31803 duplex stainless steel close to room temperature in nearly neutral $\mathrm{NaCl}$ electrolytes.

* Despite the uncertainties in the composition of the crevice-like solution, results presented here showed that similar results were obtained if the chloride content of that solution was assumed to be in the $7 \mathrm{M}$ to $12 \mathrm{M}$ range.

* Laboratory experiments and field experience with those alloys confirmed the predictions of the model.

* Although Galvele's approach does not consider metastable events taking place before stable pitting and crevice corrosion propagation, the model, proposed 40 years ago, still provides an essential theoretical framework for understanding and predicting pitting and crevice corrosion resistance.

\section{REFERENCES}

1. Galvele, J.R., J. Electrochem. Soc. 123 (1976): p. 464

2. Galvele, J.R., J.B. Lumsden, and R.W. Staehle, J. Electrochem. Soc. 125 (1978): pp. 1204-1208.

3. Oldfield, J.W., and W.H. Sutton, Br. Corros. J. 13 (1978): pp. 13-22.

4. Suzuki, T., M.U. Yamabe, and Y. Kitamura, Corrosion 29 (1973): pp. 18-22.

5. Mankowski, J., and Z. Szklarska-Smialowska, Corros. Sci. 15 (1975): pp. 493-501.
6. Frankel, G.S., J. Electrochem. Soc. 145 (1998): pp. 2186-2198.

7. Bocher, F., R. Huang, and J.R. Scully, Corrosion 66 (2010): pp. 055002-1 - 055002-15.

8. Seidell, A., Solubilities of Inorganic and Metal Organic Compounds, 4th ed. (American Chemical Society, 1958).

9. $\quad$ Carcea, A.G., E.Y.W. Yip, D.D. He, and R.C. Newman, J. Electrochem. Soc. 158 (2011): pp. C215-C220.

10. Newman, R.C., Corrosion 57 (2001): pp. 1030-1041.

11. Srinivasan, J., M.J. McGrath, and R.G. Kelly, ECS Trans. 58 (2013): pp. 1-11.

12. Pistorius, P.C., and G.T. Burstein, Philos. Trans. R. Soc. A Math. Phys. Eng. Sci. 341 (1992): pp. 531-559.

13. Sridhar, N., and D.S. Dunn, Corrosion 50 (1994): pp. 857-872.

14. Turnbull, A., Corros. Sci. 23 (1983): pp. 833-870.

15. Alavi, A., and R.A. Cottis, Corros. Sci. 27 (1987): pp. 443-451.

16. Kaji, T., T. Sekiai, I. Muto, Y. Sugawara, and N. Hara, J.

Electrochem. Soc. 159 (2012): pp. C289-C297.

17. “Norsok Standard M-001-Materials Selection" (2014).

18. "ISO 21457:2010- Petroleum, Petrochemical and Natural Gas Industries- Materials Selection and Corrosion Control for Oil and Gas Production Systems" (2010).

19. Mishra, A.K., and G.S. Frankel, Corrosion 64 (2008): pp. 836844.

20. Martinez, P.A., E.C. Hornus, M.A. Rodriguez, R.M. Carranza, and R.B. Rebak, "Crevice Corrosion Resistance of SuperAustenitic and Super-Duplex Stainless Steels in Chloride Solutions," in Corrosion 2015 (Dallas, TX: NACE International, 2015), Paper No. 5740.

21. Rincón Ortíz, M., M.A. Rodríguez, R.M. Carranza, and R.B. Rebak, Corrosion 66 (2010): pp. 105002-1-105002-12. Pourbaix, M., Atlas of Electrochemical Equilibria in Aqueous Solutions (Pergamon Press, 1966).

23. Wilde, B.E., and E. Williams, Electrochim. Acta 16 (1971): pp. 1971-1985.

24. Wilde, B.E., Corrosion 28 (1972): pp. 283-291.

25. Qvarfort, R., Corros. Sci. 29 (1989): pp. 987-993.

26. Garfias-Mesias, L.F., and J.M. Sykes, Corros. Sci. 41 (1999): pp. 959-987.

27. Salinas-Bravo, V.M., and R.C. Newman, Corros. Sci. 36 (1994): pp. 67-77.

28. Sridhar, N., and G.A. Cragnolino, Corrosion 49 (1993): pp. 885894.

29. Grimm, R.D., and D. Landolt, Corros. Sci. 36 (1994): pp. 18471868.

30. Lizlovs, E.A., and A.P. Bond, J. Electrochem. Soc. 122 (1975): pp. 719-722.

31. Newman, R.C., and T. Shahrabi, Corros. Sci. 27 (1987): pp. 827-838.

32. Ahn, M.K., H.S. Kwon, and H.M. Lee, Corros. Sci. 40 (1998): pp. 307-322.

33. Bui, N., A. Irhzo, F. Dabosi, and Y. Limouzin-Maire, Corrosion 39 (1983): pp. 491-496.

34. Laycock, N.J., and R.C. Newman, Corros. Sci. 39 (1997): pp. 1771-1790.

35. Lumsden, J.B., and S. Szklarska-Smialowska, Corrosion 34 (1978): pp. 169-178.

36. Næss, M., E.B. Haugan, R. Johnsen, and M. lannuzzi, "Effect of Tungsten on Pitting and Crevice Corrosion of Type $25 \mathrm{Cr}$ Super Duplex Stainless Steel," in Corrosion 2016 (Vancouver B.C.: NACE International, 2016), Paper No. 7308.

37. Garfias-Mesias, L.F., and J.M. Sykes, Corrosion 54 (1998): pp. 40-47.

38. Jargelius-Pettersson, R. f. ., Corros. Sci. 41 (1999): pp. 16391664.

39. Szklarska-Smialowska, Z., Pitting and Crevice Corrosion (NACE 
International, 2005).

40. Kim, J.S., and H.S. Kwon, Corrosion 55 (1999): pp. 512-521.

41. Osozawa, K., and N. Okato, Passivity and Its Breakdown on Iron and Iron Based Alloys (Houston, TX: NACE International, 1976).

42. Galvele, J.R., Corros. Sci. 21 (1981): pp. 551-579.

43. Galvele, J.R., Corros. Sci. 47 (2005): pp. 3053-3067.

44. Shaw, B.A., P.J. Moran, and P.O. Gartland, Corros. Sci. 32 (1991): pp. 707-719.

45. Frankel, G.S., L. Stockert, F. Hunkeler, and H. Boehni, Corrosion 43 (1987): pp. 429-436.

46. Scully, J.R., S.T. Pride, and H.S. Scully, "Some Correlations between Metastable Pitting and Pit Stabilization in Metals," in Crit. Factors Localized Corros. II, eds. R.G. Kelly, G.S. Frankel, and R.C. Newman (Pennington, NJ: The Electrochemical Society, 1996), p. 15.

47. Stockert, L., and H. Bohni, Mater. Sci. Forum 44-45 (1989): pp. 313-328.

48. Gravano, S.M., and J.R. Galvele, Corrosion 24 (1984): pp. 517534.

49. Schwenk, W., Corrosion 20 (1964): p. 129t-137t.

50. Kahram, M., M. Asnavandi, P. Koshy, and C.C. Sorrell, Steel Res. Int. 86 (2015): pp. 1022-1027.

51. Strandmyr, O., and O. Hagerup, "Field Experience with Stainless Steel Materials in Seawater Systems," in Corrosion 98 (NACE International, 1998), Paper No. 707.

52. Han, D., Y.M. Jiang, C. Shi, B. Deng, and J. Li, J. Mater. Sci. 47 (2012): pp. 1018-1025.

53. Pardo, A., E. Otero, M.C. Merino, M.D. López, M. V. Utrilla, and F. Moreno, Corrosion 56 (2000): pp. 411-418.

54. Zadorozne, N.S., C.M. Giordano, M.A. Rodriguez, R.M. Carranza, and R.B. Rebak, Electrochim. Acta 76 (2012): pp. 94101.

55. Hornus, E.C., C.M. Giordano, M. a. Rodríguez, R.M. Carranza, and R.B. Rebak, J. Electrochem. Soc. 162 (2015): pp. C105C113.

56. Rincón Ortíz, M., M. lannuzzi, M. Kappes, R. Carranza, and R. Rebak, "Selecting Corrosion Resistant Alloys for Seawater Applications,", Research in Progress Symposium, Paper C2014-5139, in Corrosion 2014 (NACE International, Houston, TX, 2014).

57. Bardal, E., J.M. Drugli, and P.O. Gartland, Corros. Sci. 35
(1993): pp. 257-267.

58. Skar, J.I., and S. Olsen, "Development of the NORSOK M-001 and ISO 21457 Standards - Basis for Defining Material Application Limits," in Corrosion 2016 (Vancouver B.C.: NACE International, 2016), Paper No. 7433.

\section{FIGURE CAPTIONS}

Figure 1. Cyclic polarization curves measured in 3.5 wt.\% deaerated $\mathrm{NaCl}$ solution at $25^{\circ} \mathrm{C}$, at two different potential scanning rates as indicated in each graph.

Figure 2. Potentiodynamic polarization curves measured in deaerated simulated crevice solutions at room temperature.

Figure 3. Maximum current densities measured previous to passivation or salt film formation in $\mathrm{pH} 0$ solutions with different chloride content.

Figure 4. Current vs. potential response measured during the Potentiodynamic-Galvanostatic-Potentiodynamic (PD-GS-PD) experiment on UNS S31803 duplex stainless steel in $3.5 \mathrm{wt} . \% \mathrm{NaCl}$ at room temperature (left) and potential vs. time evolution during the GS step (right). The picture insert at the right shows a macrograph of the sample at the end of the test. As a reference, the size of the hole is 7 $\mathrm{mm}$. 
Table 1

Chemical composition of the duplex stainless steels samples in wt.\%.

\begin{tabular}{|c|c|c|c|c|c|c|c|c|c|c|c|c|c|c|}
\hline UNS & $\mathrm{C}$ & $\mathrm{Si}$ & $\mathrm{Mn}$ & $\mathrm{P}$ & $\mathrm{S}$ & $\mathrm{Cr}$ & $\mathrm{Mo}$ & $\mathrm{Ni}$ & $\mathrm{W}$ & $\mathrm{Cu}$ & $\mathrm{Co}$ & $\mathrm{N}$ & $\mathrm{Fe}$ & $\mathrm{PRE}_{\mathrm{N}, \mathrm{W},}$ \\
\hline S32750 & 0.02 & 0.32 & 0.56 & 0.019 & 0.0004 & 25.74 & 3.31 & 6.92 & 0.55 & 0.20 & 0.05 & 0.267 & bal & 41.84 \\
\hline S31803 & 0.024 & 0.29 & 1.49 & 0.025 & 0.0010 & 22.25 & 3.17 & 6.50 & - & - & - & 0.1815 & bal & 35.615 \\
\hline
\end{tabular}

Table 2

Diffusion limited current densities measured in $9 \mathrm{M} \mathrm{LiCl,} \mathrm{pH} 0$ and 12 M LiCl, pH 0

\begin{tabular}{|c|c|c|c|}
\hline \multirow{2}{*}{ Alloy } & \multicolumn{2}{|c|}{$\mathrm{i}_{\text {lim }}\left(\mathrm{A} / \mathrm{cm}^{2}\right)$} & \multirow{2}{*}{$\frac{i_{\text {lim }}^{\left[C \mathrm{C}^{-}\right]=9 \mathrm{M}}}{i_{\text {lim }}^{\left[C l^{-}\right]=12 \mathrm{M}}}$} \\
\cline { 2 - 3 } & $\mathrm{LiCl} 9 \mathrm{M}, \mathrm{pH} \mathrm{0}$ & $\mathrm{LiCl} \mathrm{12} \mathrm{M,} \mathrm{pH} \mathrm{0}$ & \\
\hline UNS S31803 & 0.0640 & 0.0281 & 2.27 \\
\hline UNS S32750 & 0.0468 & 0.0275 & 1.70 \\
\hline
\end{tabular}

Table 3

Prediction of crevice corrosion critical potential based on Galvele's model

\begin{tabular}{|c|c|c|c|}
\hline Parameter & Crevice-like Solution & UNS S31803 & UNS S32750 \\
\hline \multirow{3}{*}{$E_{O C}^{*}\left(\mathrm{~V}_{\mathrm{SCE}}\right)$} & $7 \mathrm{M} \mathrm{Cl}^{-} \mathrm{pH} 0$ & -0.331 & -0.341 \\
\hline & $9 \mathrm{M} \mathrm{Cl}^{-} \mathrm{pH} 0$ & -0.321 & -0.317 \\
\hline & $12 \mathrm{M} \mathrm{Cl}^{-} \mathrm{pH} 0$ & -0.325 & -0.295 \\
\hline \multirow{3}{*}{$\eta\left(V_{S C E}\right)$} & $7 \mathrm{M} \mathrm{Cl}^{-} \mathrm{pH} 0$ & 0.164 & 0.158 \\
\hline & $9 \mathrm{M} \mathrm{Cl}^{-} \mathrm{pH} 0$ & 0.131 & 0.127 \\
\hline & $12 \mathrm{M} \mathrm{Cl}^{-} \mathrm{pH} 0$ & 0.165 & 0.154 \\
\hline \multirow{3}{*}{$E_{\text {crit }}\left(V_{S C E}\right)$} & $7 \mathrm{M} \mathrm{Cl}^{-} \mathrm{pH} 0$ & -0.197 & -0.183 \\
\hline & $9 \mathrm{M} \mathrm{Cl}^{-} \mathrm{pH} 0$ & -0.190 & -0.190 \\
\hline & $12 \mathrm{M} \mathrm{Cl}^{-} \mathrm{pH} 0$ & -0.160 & -0.141 \\
\hline
\end{tabular}




\section{Figures}
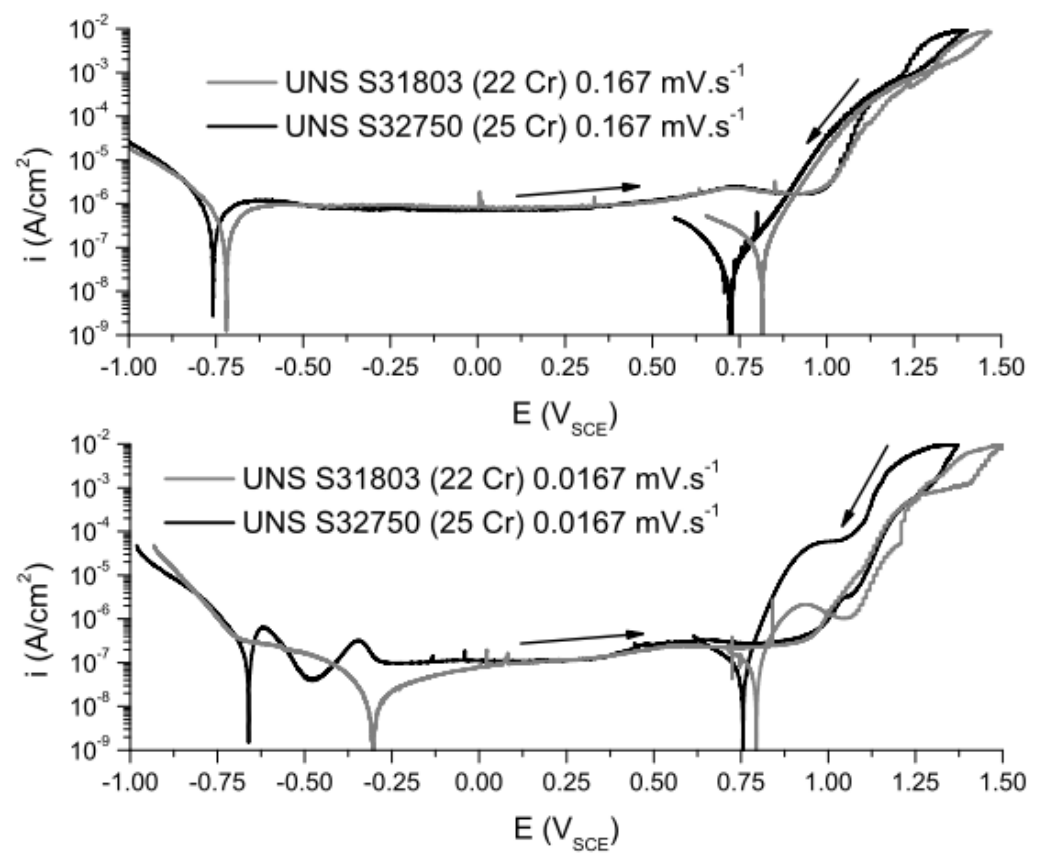

Figure 1: Cyclic polarization curves measured in 3.5 wt. $\%$ deaerated $\mathrm{NaCl}$ solution at $25^{\circ} \mathrm{C}$, at two different potential scanning rates as indicated in each graph. 


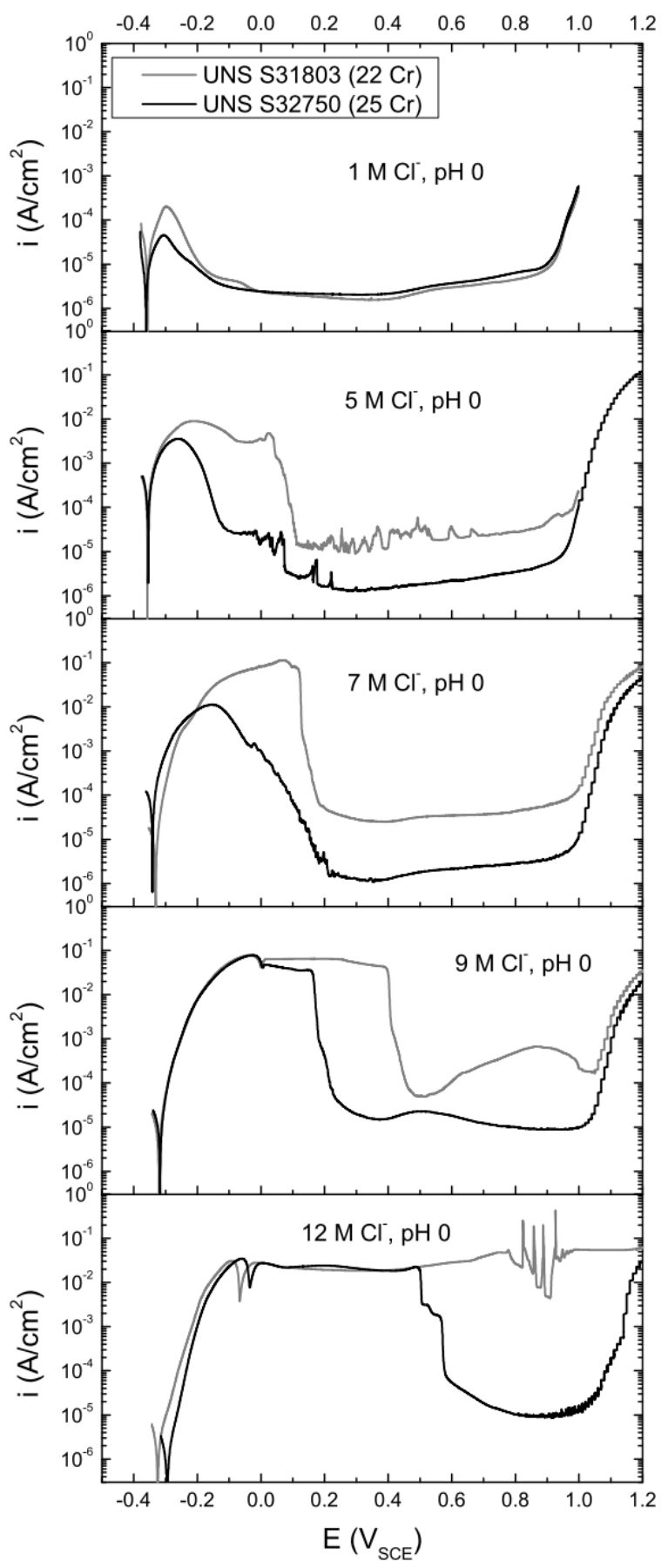

Figure 2: Potentiodynamic polarization curves measured in deaerated simulated crevice solutions at room temperature. 


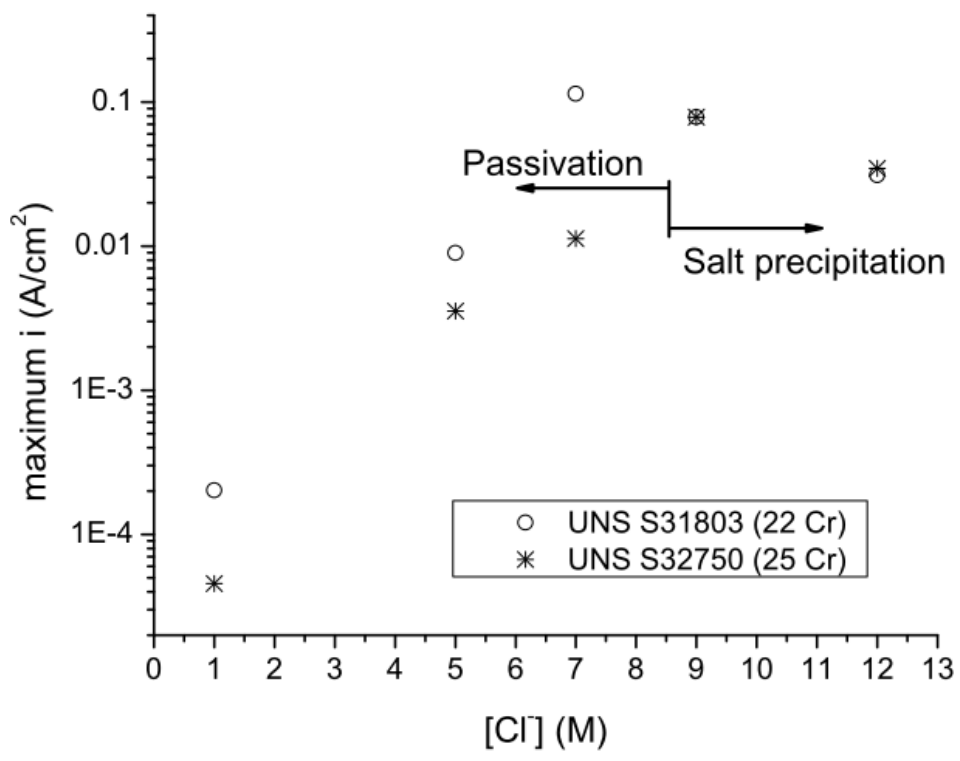

Figure 3: Maximum current densities measured previous to passivation or salt film formation in $\mathrm{pH} 0$ solutions with different chloride content. 

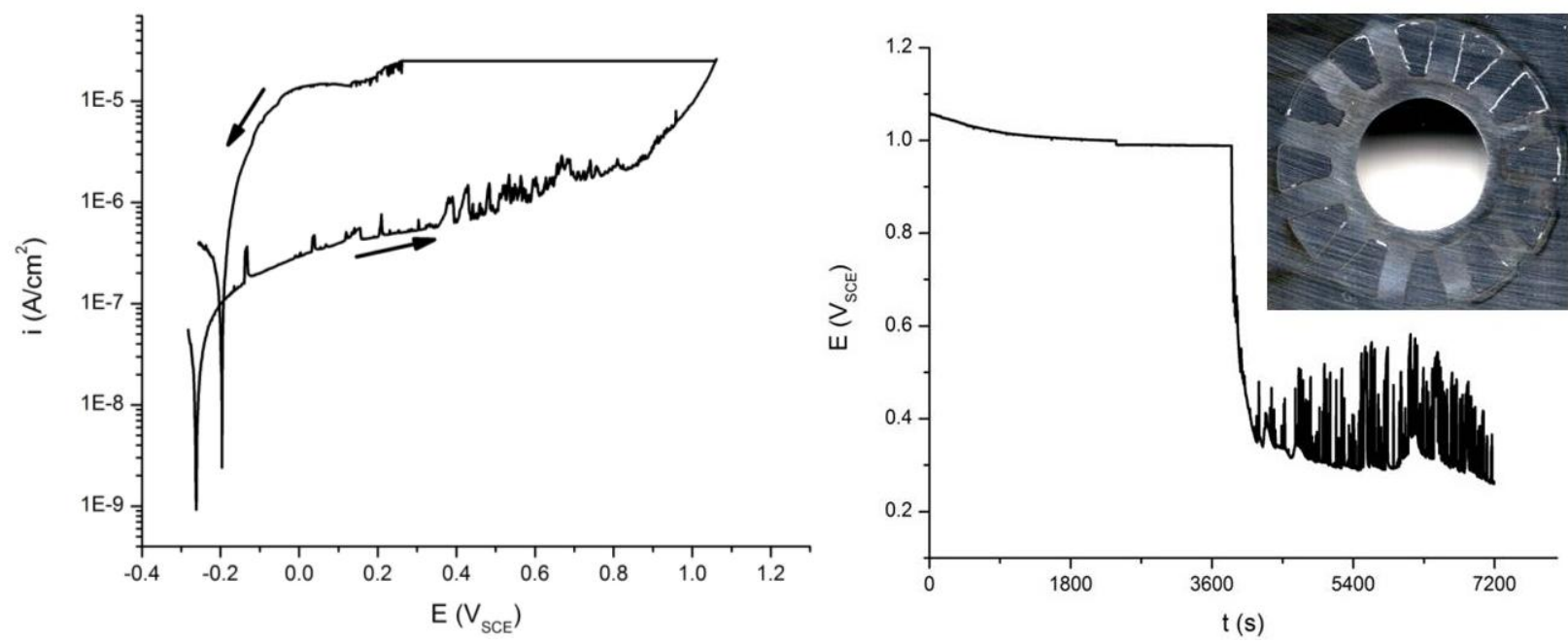

Figure 4: Current vs. potential response measured during the Potentiodynamic-Galvanostatic-

Potentiodynamic (PD-GS-PD) experiment on UNS S31803 duplex stainless steel in 3.5 wt.\% $\mathrm{NaCl}$ at room temperature (left) and potential vs. time evolution during the GS step (right). The picture insert at the right shows a macrograph of the sample at the end of the test. As a reference, the size of the hole is $7 \mathrm{~mm}$. 

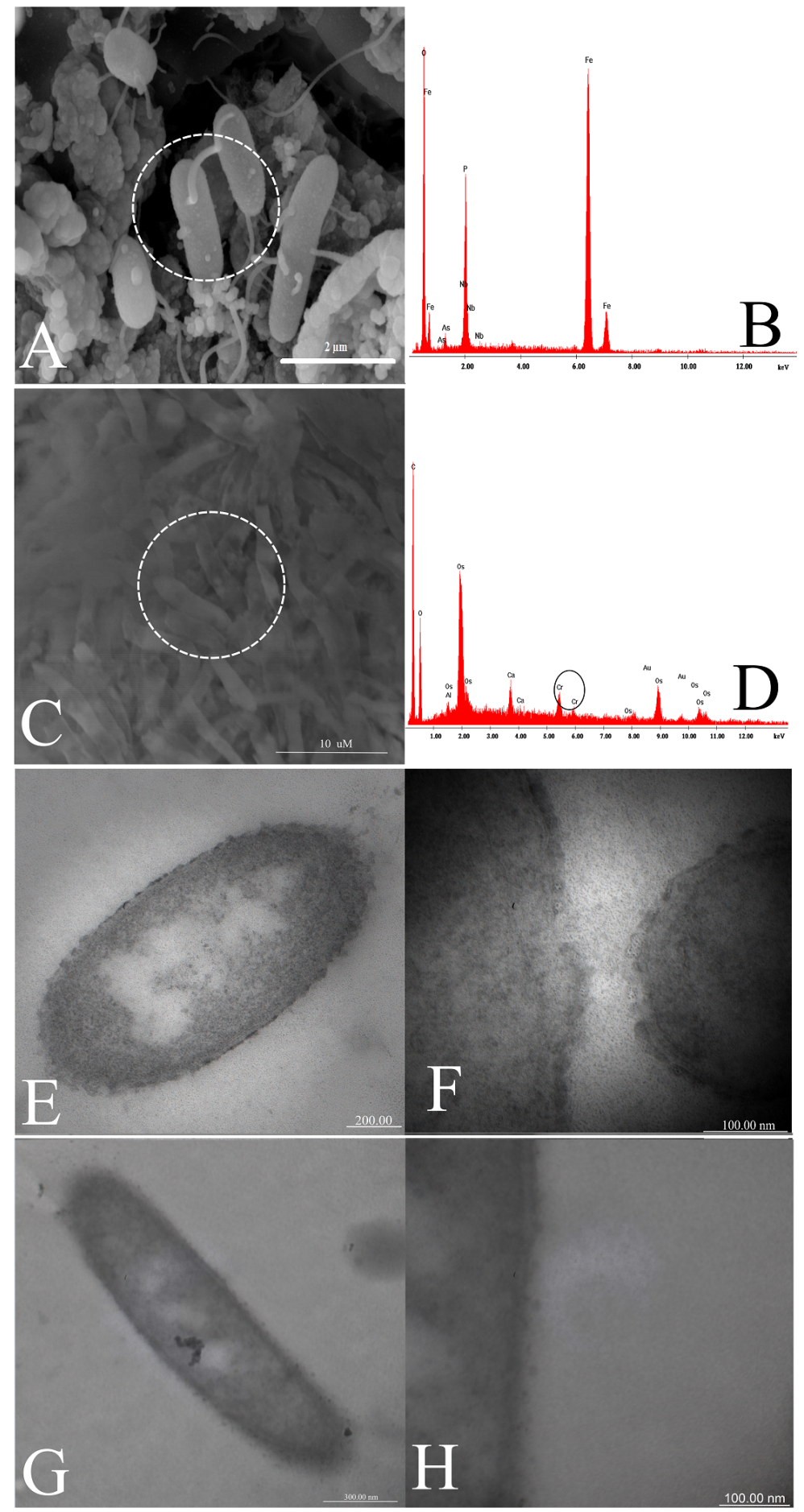

SI 1. Scanning electron micrograph of S. oneidensis MR-1 under normal conditions (A), EDS spectrum of S. oneidensis MR-1 under normal conditions (B). Scanning electron micrograph of S. oneidensis upon reduction of $\mathrm{Cr}(\mathrm{VI})(\mathrm{C})$, EDS spectrum of $\mathrm{Cr}$ (III) precipitates on cell surfaces (D), and transmission electron micrographs (TEM) of S. oneidensis MR-1 upon reduction of $\mathrm{Cr}$ (VI) (E-H). Panels E and F are TEM of uranyl acetate-stained cells, while panels $\mathrm{G}$ and $\mathrm{H}$ are TEM of unstained cells. The dashed circle in panels $\mathrm{A}$ and $\mathrm{C}$ indicate regions evaluated by EDS. 